Kohl: a Journal for Body and Gender Research

Vol. 6, No. 1 (Summer 2020)

\title{
solidarity is not a slogan
}

\author{
Taylor Miller
}


Kohl 6.1

12 gash (noun)

I'gash

1 : a deep long cut in flesh

2: a deep narrow depression or cut

Reminders on the corner to nudge us out of routine, complicity. A curious cartography of visual resistance. The who and the when and the what now, repeated in my privilege of movement. Easily passed by, but easy to stop and heed the message. A sign in the city that there's someone, somewhere, thinking about reinscribing space to value those dispossessed, paved over, silenced.

Yet - stickers and scrawls have all been scratched, torn, defaced. A half-life of wheatpastings, barely legible after the violence and rain. Opposition on the street, efforts to stymie these attempts at movement building and solidarity. Palpable tension in text. Each city reading the same. Mark-making, image-taking. Taking. Remember I am not doing enough. 


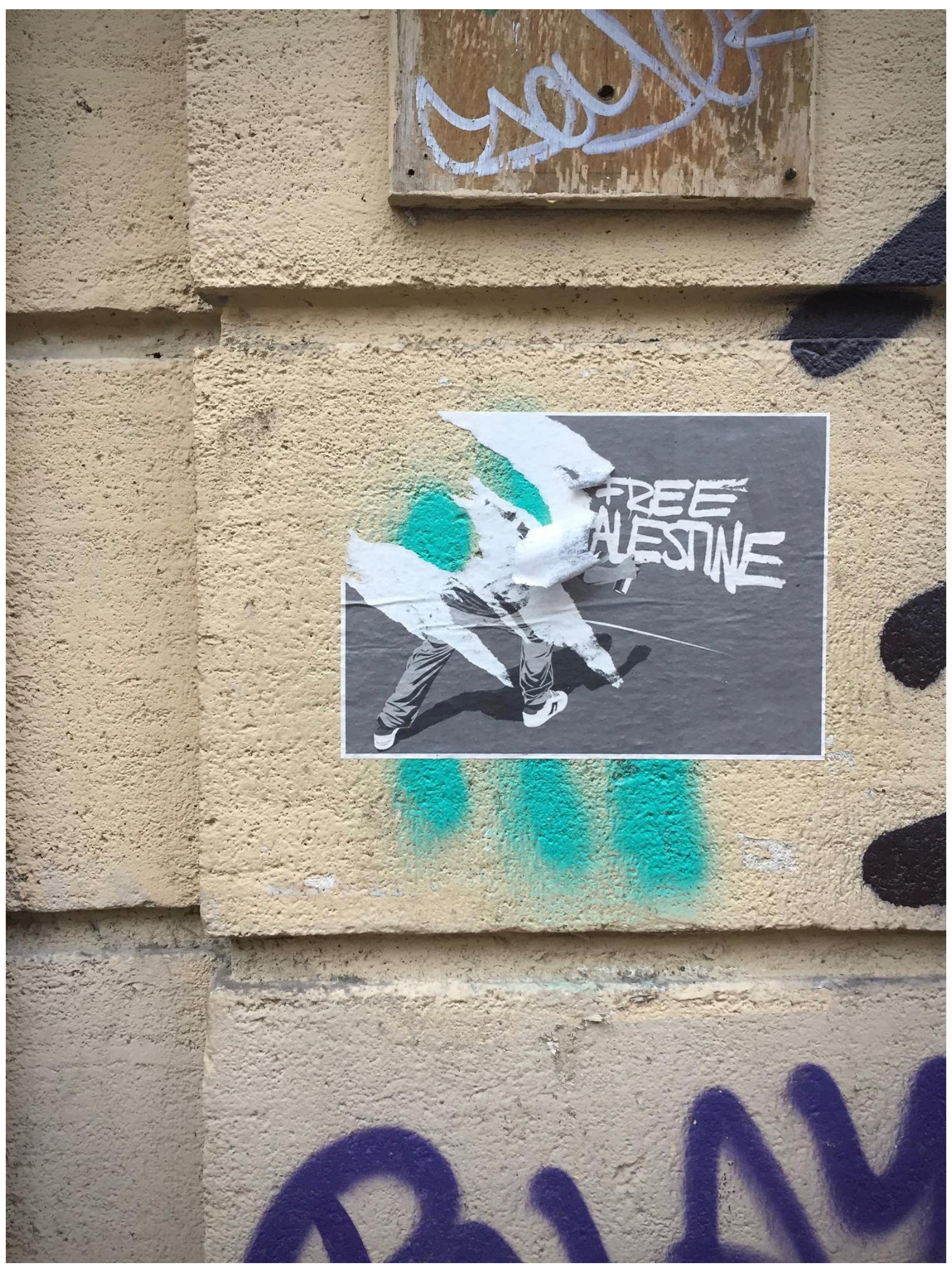

Image 1 - (2018) Noailles, Marseille 


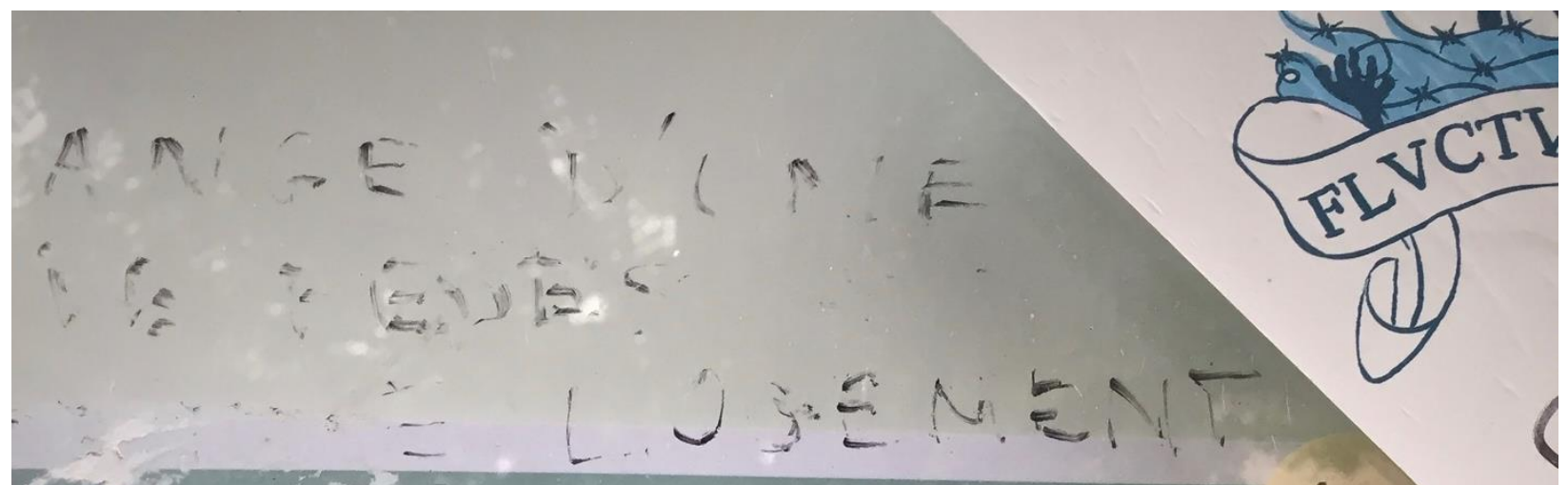

Emirre complet sur feţed elanature.coi

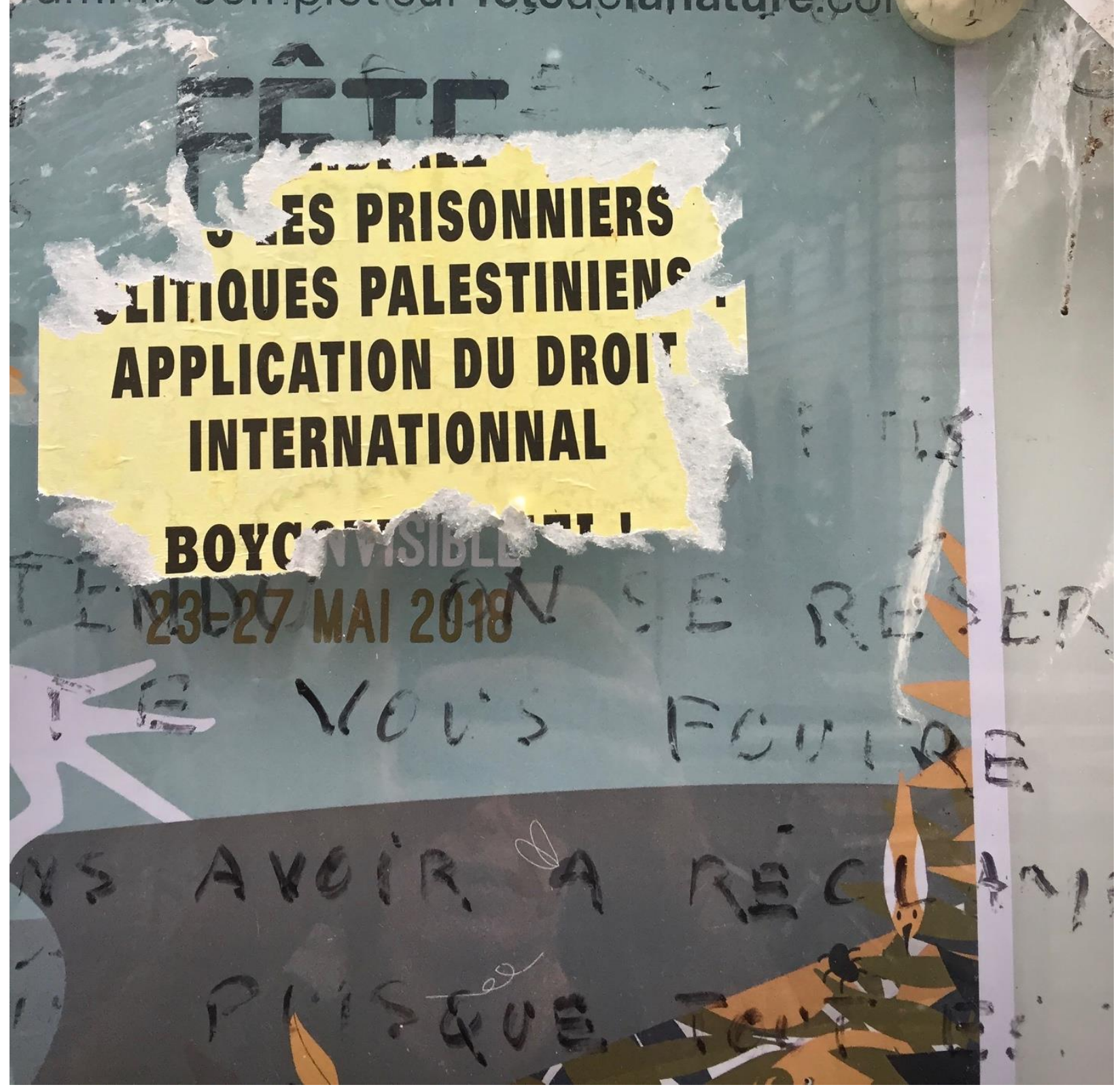

Image 2 - (2020) Canal Saint Martin, Paris 


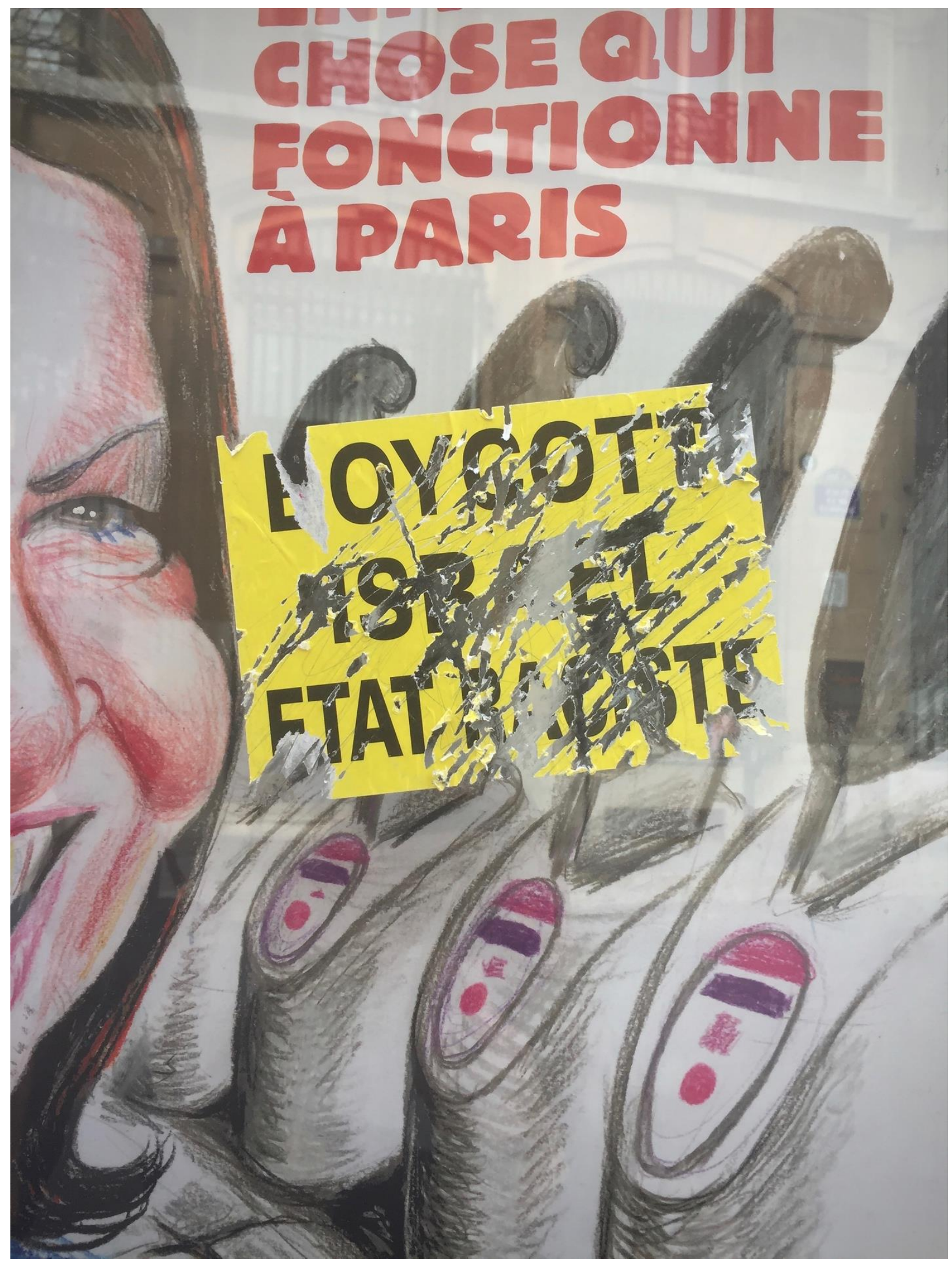


Kohl 6.1

16

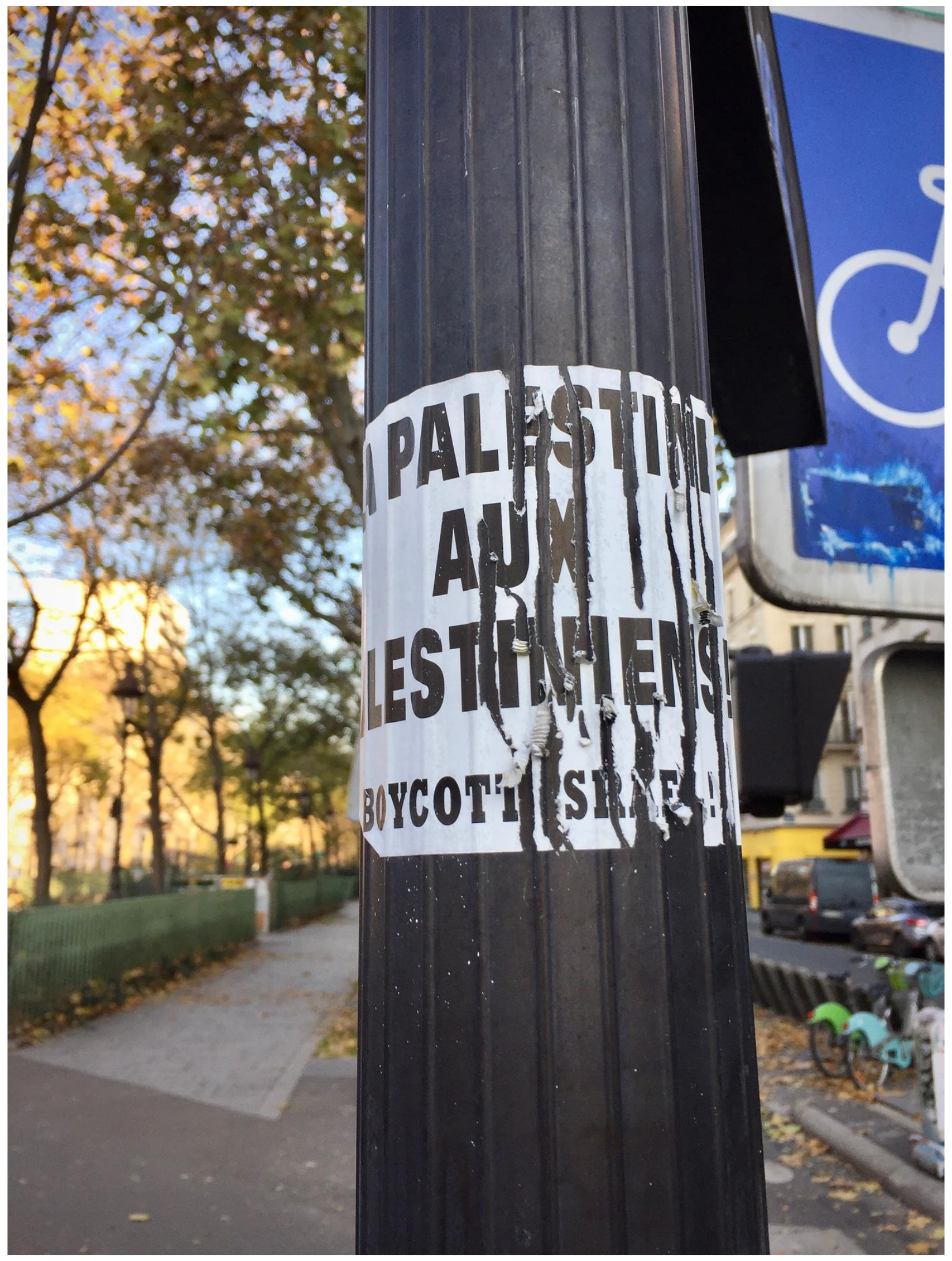

Image 4 - (2019) Bastille, Paris 


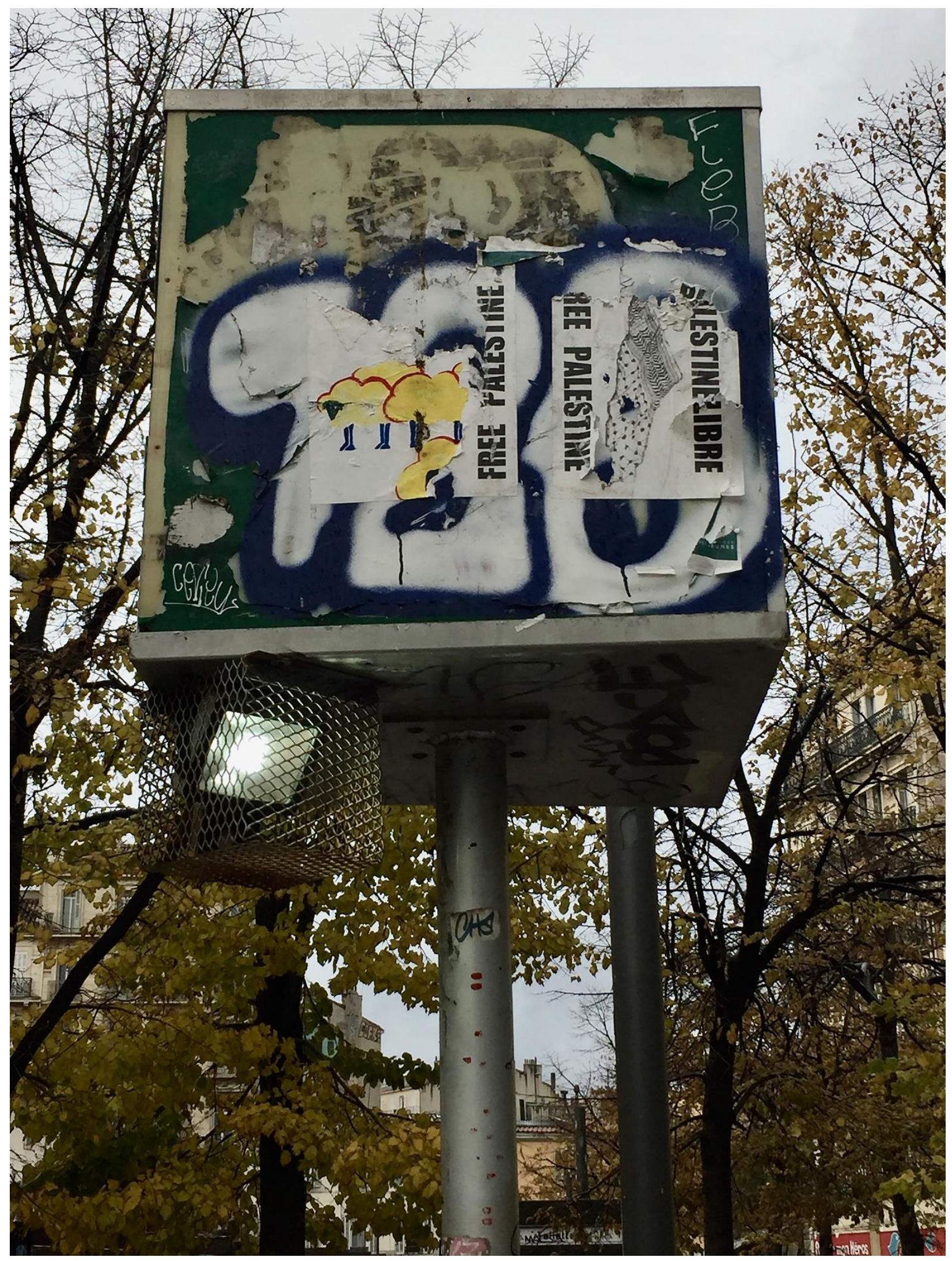

Image 5 - (2019) Belle de Mai, Marseille 
Kohl 6.1

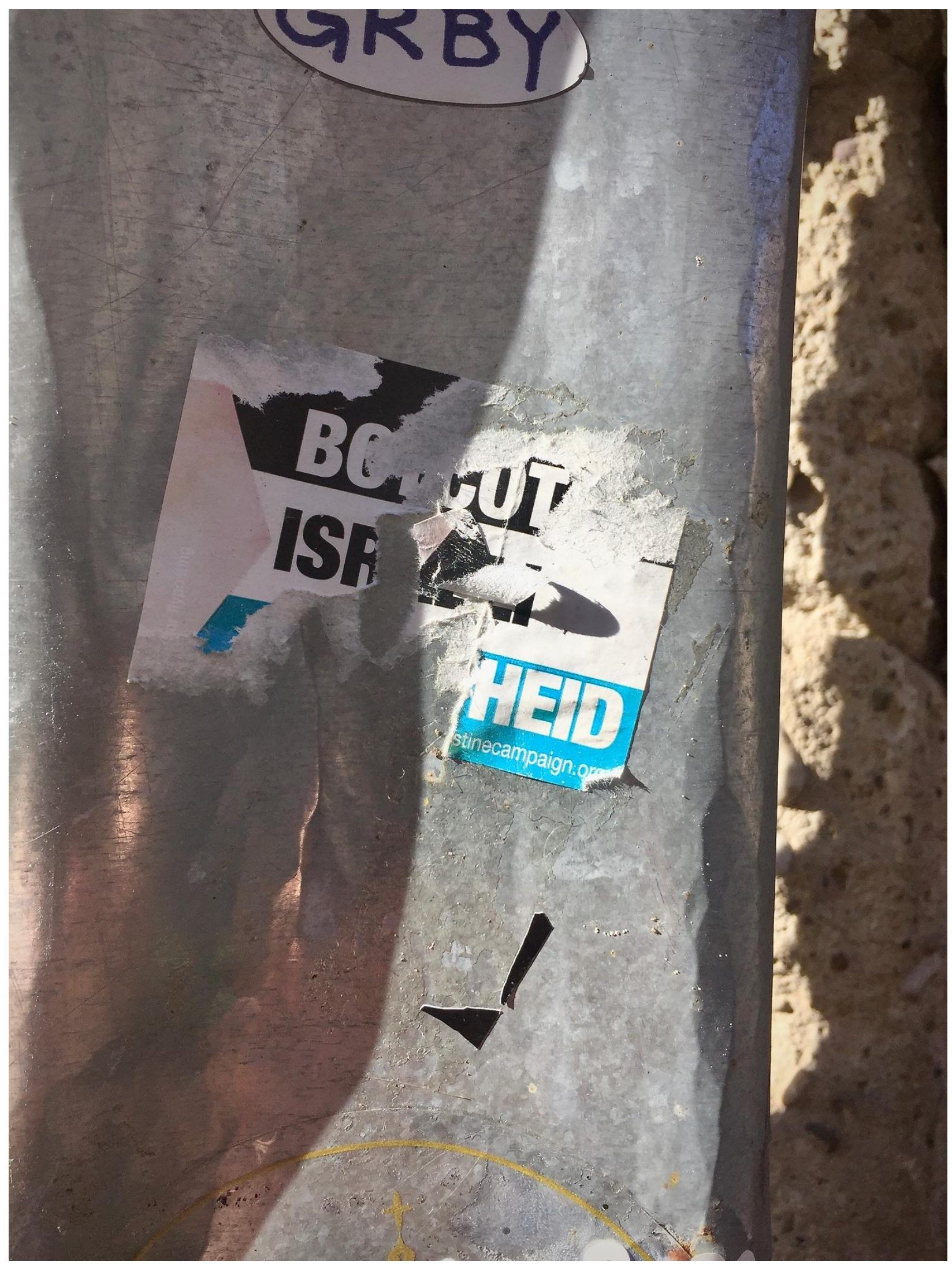

Image 6 - (2019) Kaptol, Zagreb 


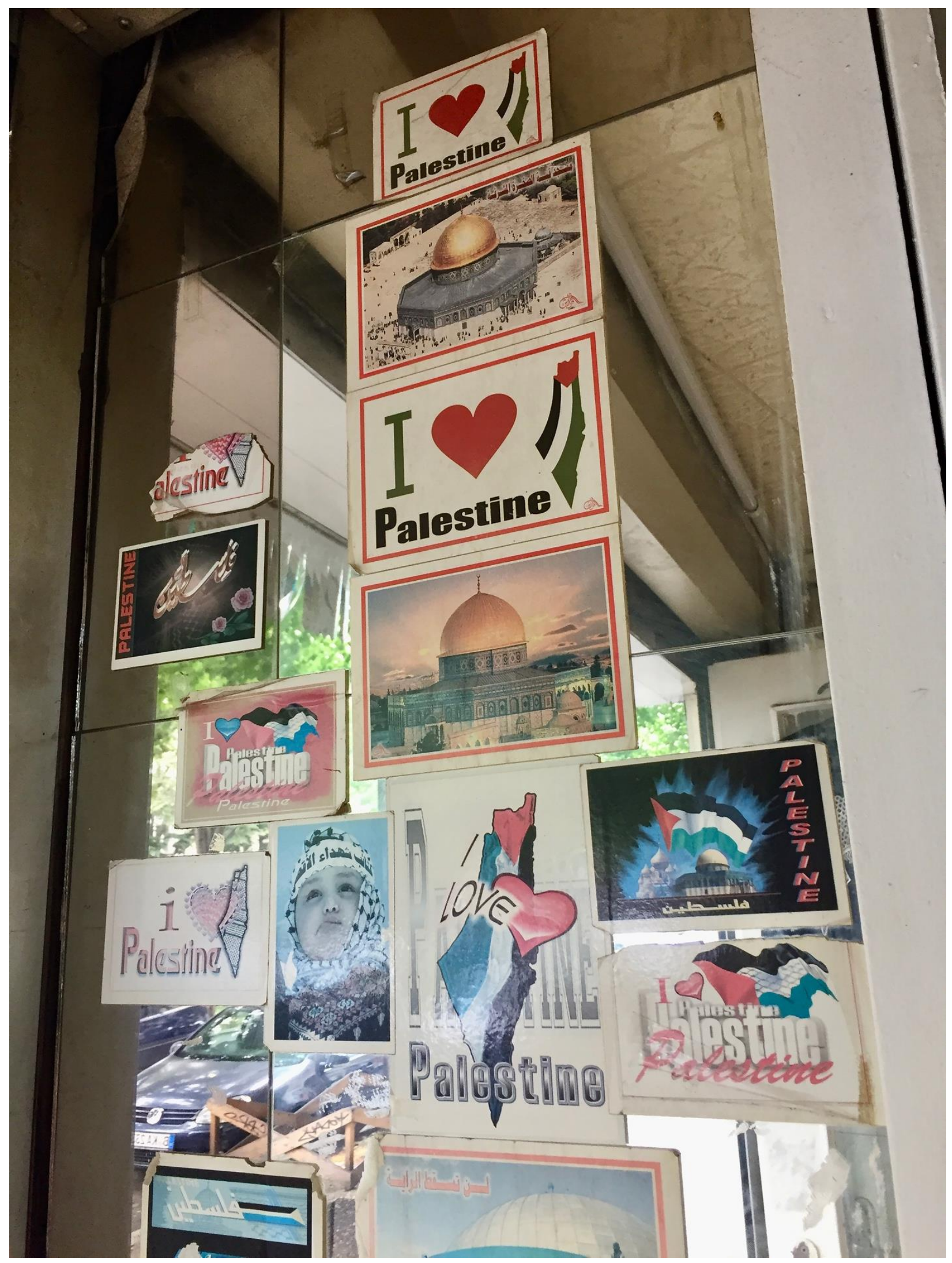


Kohl 6.1

20

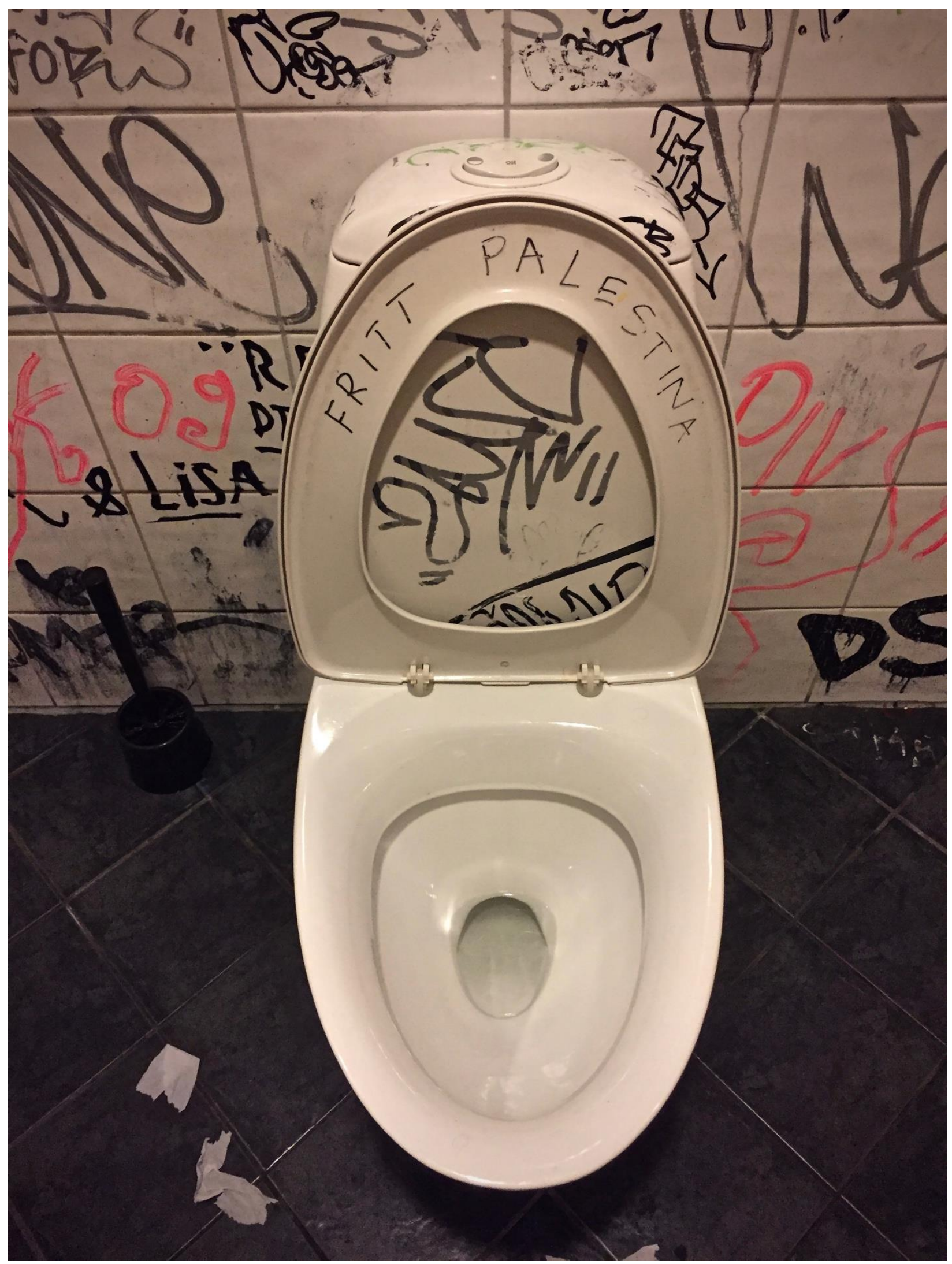

Image 8 - (2018) Grünerløkka, Oslo 


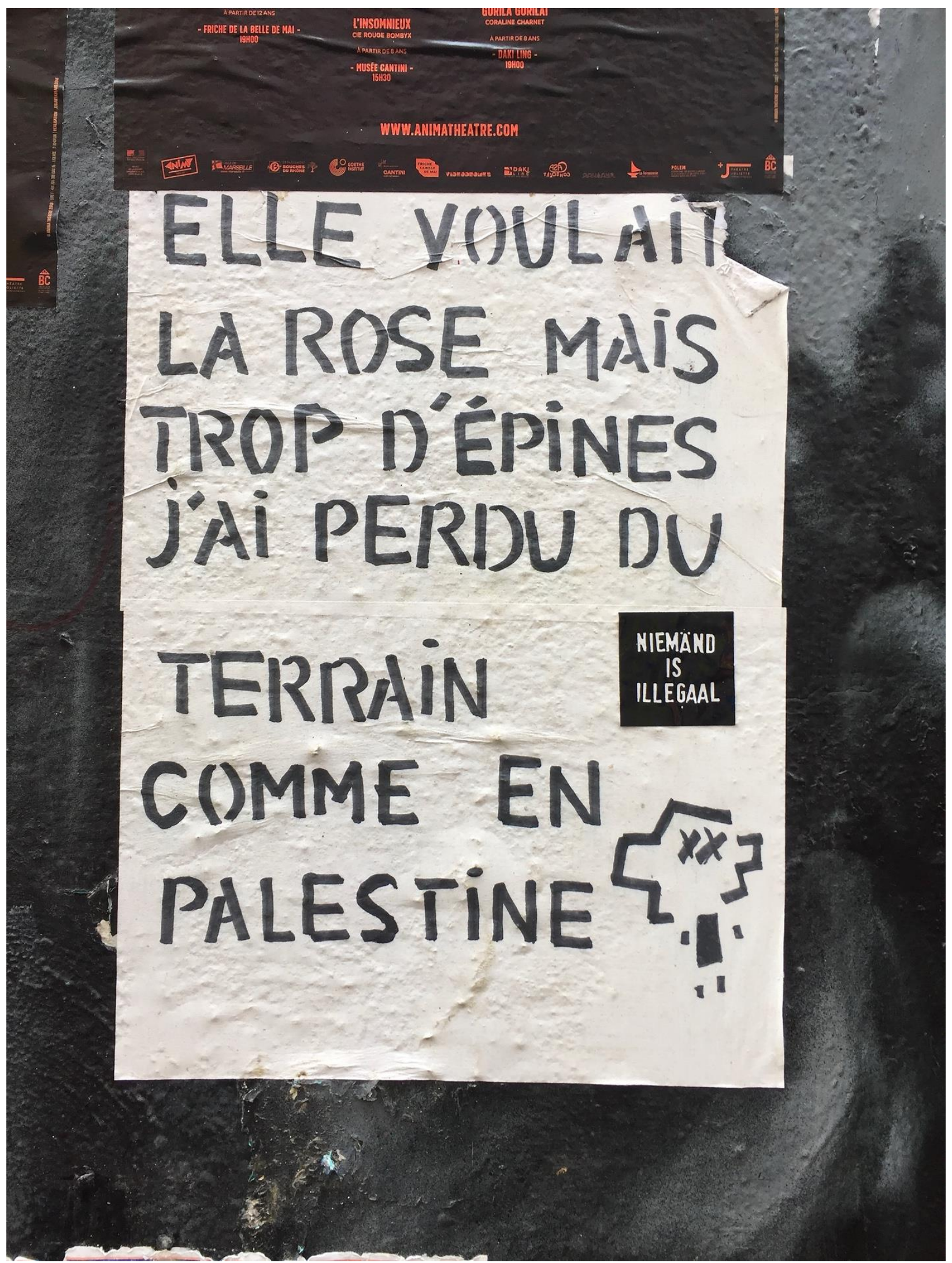


Kohl 6.1

22

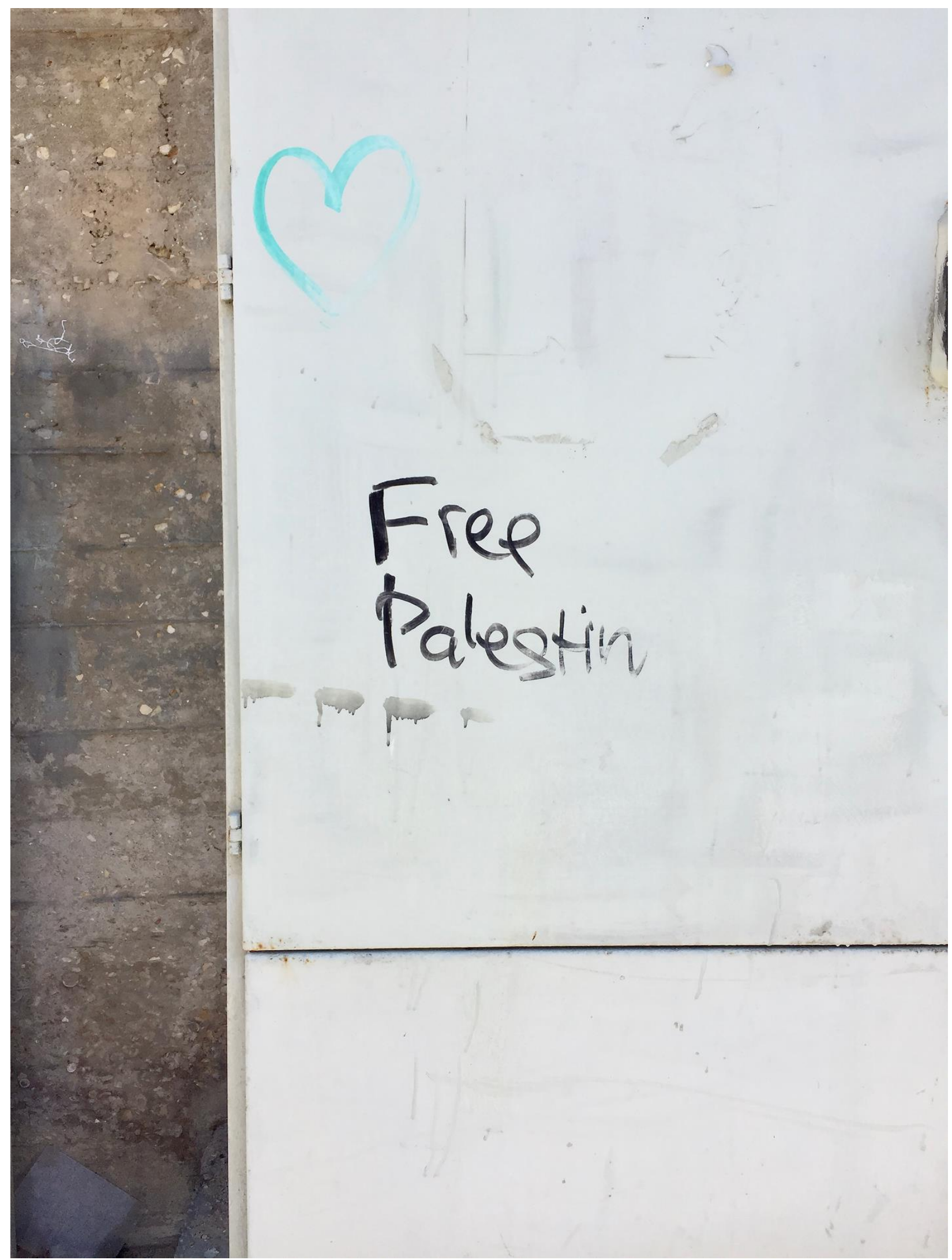

Image 10 - (2018) Ajami, Jaffa 